\title{
Producing Polymer Fibers by Electrospinning in Supercritical Fluids
}

\author{
Lu Li, ${ }^{1}$ Zhao Jiang, ${ }^{1}$ Qi Pan, ${ }^{2}$ and Tao Fang ${ }^{1}$ \\ ${ }^{1}$ Department of Chemical Engineering, Xian Jiaotong University, Xian, Shaanxi 710049, China \\ ${ }^{2}$ Department of Process Equipment and Control Engineering, Xi'an Jiaotong University, Xian, Shaanxi 710049, China \\ Correspondence should be addressed to Tao Fang; taofang@mail.xjtu.edu.cn
}

Received 7 January 2013; Revised 13 March 2013; Accepted 25 March 2013

Academic Editor: Giuseppe Caputo

Copyright (c) $2013 \mathrm{Lu} \mathrm{Li}$ et al. This is an open access article distributed under the Creative Commons Attribution License, which permits unrestricted use, distribution, and reproduction in any medium, provided the original work is properly cited.

\begin{abstract}
Nanofibers have a wide range of applications, including filtration and biomedical engineering. Porous or hollow fibers with large surface-to-volume ratios are more popular in some fields than the common nanofibers. Porous nanofibers can be obtained through electrospinning with highly volatile solvents or through special treatment following electrospinning. A new process where electrospinning is conducted in supercritical or near-critical $\mathrm{CO}_{2}$ to produce porous or hollow nanofibers has been summarized. In addition, a process entailing compressed $\mathrm{N}_{2}$-assisted electrospinning was attempted to produce PVP nanofibers in this work, but it was proved to be unsuccessful. Since the fiber morphologies are dependent on the phase behavior of organic solvents in supercritical fluids, ASPEN PLUS 2006 was used to simulate the phase equilibrium of the solvent-supercritical fluid system to explain why porous or hollow fibers can be obtained in compressed $\mathrm{CO}_{2}$, but not in compressed $\mathrm{N}_{2}$.
\end{abstract}

\section{Introduction}

Electrospinning is one of the most intriguing and efficient processes used to produce a variety of polymer fibers. Besides, fiber diameters can range from several microns to tens of nanometers, and as small as $10 \mathrm{~nm}$ [1-3]. The electrospinning process uses a high electrical field to induce charged polymer droplets. As the solution jet travels, it is elongated and whipped continuously by the electrical force, accompanied by the evaporation of solvent. The fibers are formed when they are deposited on the oppositely charged collector [4-6].

In general, fibers, produced by electrospinning, have a smooth surface and solid-core cross-section. These fibers have been used in protective clothing, filtration, catalysis, biosensors, tissue engineering, and so forth [7-9]. In addition, the special performance of nanofibers can be enhanced as specific surface area increases. Consequently, fibers that possess specific structures, such as hollow, coresheath, and porous surface, can offer advantage for a number of applications. For instance, these "special fibers" are ideal alternatives in drug delivery, tissue engineering scaffolds, filter applications, or as templates for forming functional nanotubes [10-13].

Nowadays, porous polymer fibers or fibers with a large specific surface area have been produced using a special electrospinning process $[14,15]$. Bognitzki et al. [16] initially reported that porous nanofibers could be directly fabricated by electrospinning. The mechanism that generates the pore structure of the fibers during electrospinning is a phase separation caused by rapid evaporation of the system's solvent leading to the subsequently rapid solidification of polymer $[16,17]$. However, a second mechanism responsible for formation of pores in these fibers is under consideration is the "breath figure" $[18-20]$. It has been demonstrated that the humidity of the experimented environment directly affects the surface morphology of electrospun fibers $[19,20]$. Meanwhile, porous polymer fibers can also be produced through electrospinning polymer blends, followed by selective removal of one of the components [21]. In conclusion, the after processing is usually solvent extraction [22-24], thermal treatment [25], light crosslinking [26, 27], and chemical reaction $[10,28]$. 


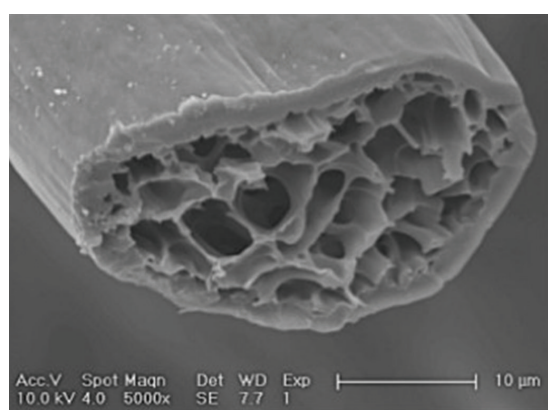

(a)

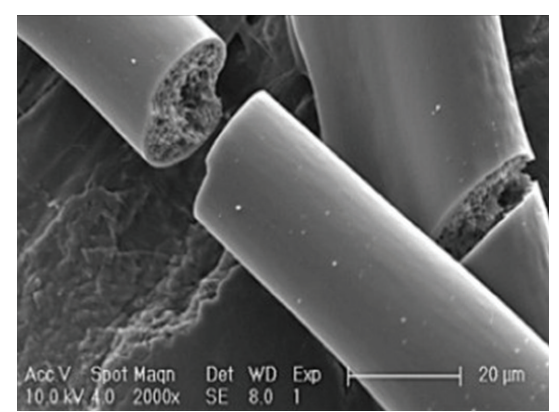

(b)

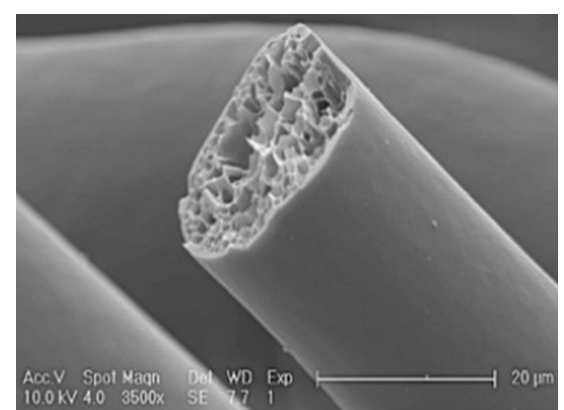

(c)

FIGURE 1: SEM images of PVP fiber morphologies obtained by electrospinning into a $\mathrm{CO}_{2}$ bath at $295 \mathrm{~K}$ and (a) 3.45 ; (b) 4.83; and (c) $4.96 \mathrm{MPa}$ [41].

Supercritical fluid has been successfully exploited to form microstructure in polymer processing. Process examples include, supercritical foaming $[29,30]$ and emulsion templating [31]. It is noticeable that nonsolvent-induced phase separation (NIPS) is another versatile method that can be employed to form porous polymer fibers and polymeric membranes $[32,33]$. It has been suggested that compressed gas or supercritical fluid can be good alternatives to nonsolvent in polymer processing of porous materials [34].

\section{Electrospinning in Supercritical or Near-Critical $\mathrm{CO}_{2}$}

In addition to being a good solvent for most of organic polymers [35], supercritical $\mathrm{CO}_{2}\left(\mathrm{scCO}_{2}\right)$ is also inexpensive, environmentally safe, and readily available. $\mathrm{ScCO}_{2}$ facilitates the absorption of desirable additives under appropriate conditions [36]. Therefore, $\mathrm{scCO}_{2}$ or near-critical $\mathrm{CO}_{2}$ offer great potential as nonsolvent in electrospinning processes for preparing porous or nanofibers with novel morphologies [30]. This approach is analogous to the process, known as "precipitation with a compressed fluid antisolvent" (PCA). Some researchers have reported that an organic polymer solution can be sprayed through a capillary tube into compressed carbon dioxide to generate porous or hollow fibers [37-39]. Levit and Tepper [40] firstly proposed a $\mathrm{scCO}_{2}$ assisted electrospinning process in which the needleless electrospinning system was placed into a vessel filled with $\mathrm{scCO}_{2}$. The solid poly(dimethylsiloxane) (PDMS) and poly(D, Llactic acid) (PLA) fibers were obtained against gravity in a bath of $\mathrm{scCO}_{2}$, whereas no fibers were obtained when the electrospinning was performed in air. It is explained that the supercritical solvent softens rather than dissolving or liquefying the polymer, which reduces the viscosity of the undissolved polymer for electrospinning.

Based on their pioneering work, Shen et al. [41] developed and patented [42] a vessel in which the polymer solution could be electrospun in a near-critical $\mathrm{CO}_{2}$. Using this device, the authors prepared PVP nanofibers with a porous internal structure and a coherent external skin. These materials were produced, when a PVP/dichloromethane (DCM) solution was electrospun at $3.45,4.83$, and $4.96 \mathrm{MPa}$, as seen in
Figure 1. However, under ambient conditions, with a PVP/ DCM solution, electrospun PVP nanofibers with solid core were produced [20]. Presence of $\mathrm{scCO}_{2}$ or near-critical $\mathrm{CO}_{2}$ accelerates the solution phase separation. The compressed $\mathrm{CO}_{2}$ extracts solvent (DCM), enhancing mass transfer and rapid drying of the polymer. As a result, the coherent external skin takes shape on the polymer fibers. In addition, due to the rapid diffusion of $\mathrm{CO}_{2}$ into the polymer solution jet, compressed $\mathrm{CO}_{2}$ also plays the role as a porogen facilitating the formation of the interior porous structure in this process.

Lee et al. [43] proposed a similar procedure to produce PVP nanofibers by electrospinning in a bath of compressed $\mathrm{CO}_{2}$. Hollow PVP fibers were produced, with diameter ranging from 400 to $900 \mathrm{~nm}$. The presence of $\mathrm{CO}_{2}$ contributes to removal of organic solvent, which effectively eliminates the formation of beads. Since $\mathrm{scCO}_{2}$ is a potential swelling agent for polymers [36], the diameters of fibers that are electrospun in near-critical or supercritical $\mathrm{CO}_{2}$ are larger than those obtained under atmosphere conditions. In addition, Liu et al. [44] improved the experimental apparatus by increasing the nozzle-to-target distance. To demonstrate the impact of compressed $\mathrm{CO}_{2}$ on the fiber morphology, several polymer solutions were tested. Nanofibers obtained from PVP/ethanol solution exhibited a single hollow core and a ribbon-like morphology when the pressure exceeded 5.6 MPa. Porous PVDF fibers were formed from poly(vinylidene fluoride) (PVDF)/dimethylacetamide (DMAc) solution and PVDF/dimethylformamide (DMF) solution electrospun into a saturated $\mathrm{CO}_{2}$ vapor. It was suggested that the morphologies of fibers depend not only on the operating conditions (pressure and temperature) of $\mathrm{CO}_{2}$, but also on phase behavior of the organic solvent in $\mathrm{CO}_{2}$. It is now understood that the saturated $\mathrm{CO}_{2}$ has two important impacts on $\mathrm{scCO}_{2}$-assisted electrospinning process. The first is the rapid diffusion of $\mathrm{CO}_{2}$ in the solution jet which induces phase separation of the polymer solution. The second involves excess $\mathrm{CO}_{2}$ which extracts solvent from the solution jet. These two effects are responsible for the porous or hollow nanofibers being formed when a polymer/solvent solution was electrospun in compressed $\mathrm{CO}_{2}$, but not in ambient air.

Wahyudiono et al. [45] developed an apparatus similar to that of Liu et al. [44] to electrospin PVP-DCM solution 


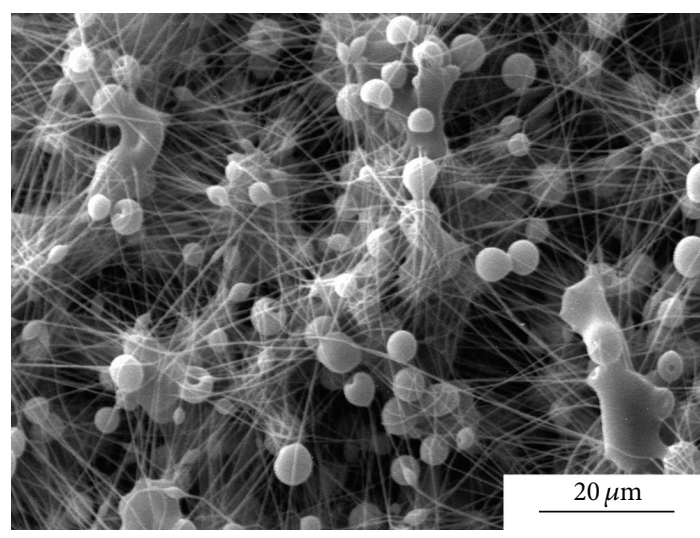

(a)

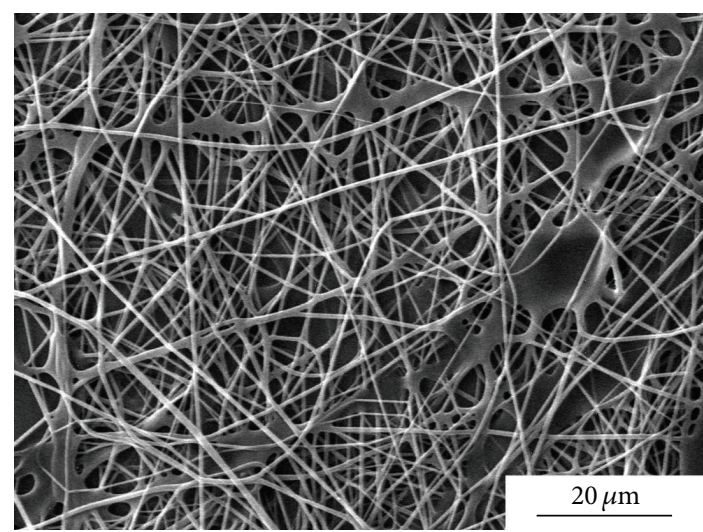

(c)

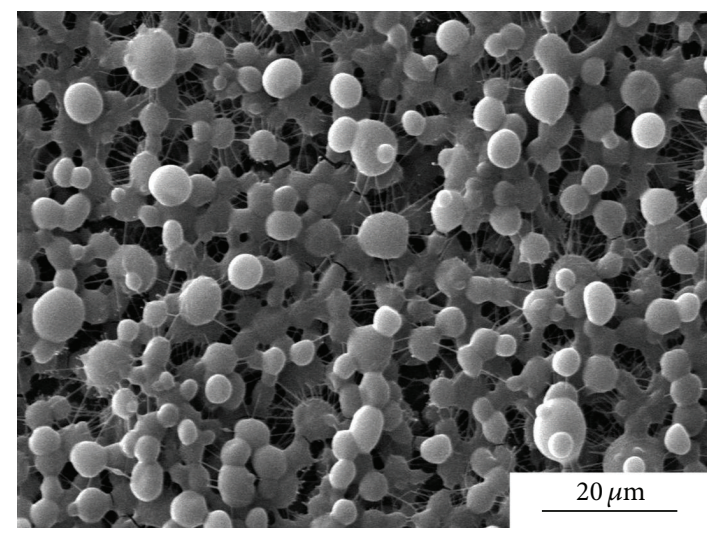

(b)

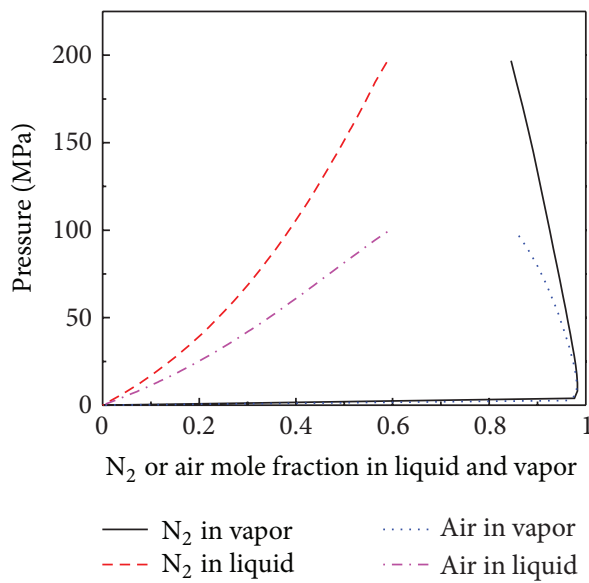

(d)

FIGURE 2: SEM of PVP fibers created by electrospinning a 5 wt\% PVP-DCM solution into $\mathrm{N}_{2}$ at $298 \mathrm{~K}$ and (a) $2.5 \mathrm{MPa}$; (b) $5 \mathrm{MPa}$; (c) $7.5 \mathrm{MPa}$, and (d) simulated binary phase equilibrium for $\mathrm{N}_{2}$-DCM and air-DCM solutions.

into pressurized $\mathrm{CO}_{2}$ (at 2, 4, and $8 \mathrm{MPa}$ ), but it was unsuccessful in producing hollow or porous PVP fibers. Generally speaking, as $\mathrm{CO}_{2}$ pressure rises, the diameter of nanofibers increases, and the formation of polymer beads ends. This effect results from rapid evaporation of DCM in $\mathrm{CO}_{2}$ which influences the polymer solution's concentration and phase separation progress [46]. In addition, the polymer is swelled by $\mathrm{scCO}_{2}$ [47]. In this vein, Wahyudiono et al. [48] used FT-IR spectroscopy to analyze the polymer product, and they found that the structural properties of PVP fibers do not change after electrospinning in pressurized $\mathrm{CO}_{2}$. This suggests that near- or $\mathrm{scCO}_{2}$ offers great potential to improve devolatilization of solvents during electrospinning.

In conclusion, near- or $\mathrm{scCO}_{2}$-assisted electrospinning has been used to produce hollow and porous fibers. It has been found that the state of the $\mathrm{CO}_{2}$ affects the miscibility of solvent- $\mathrm{CO}_{2}$ system and the rate of solution phase separation during the electrospinning jet's flight time [44]. As a result, it is possible to produce fibers with different morphologies by regulating $\mathrm{CO}_{2}$ pressure and temperature of the electrospinning process.

\section{Electrospinning in Compressed Nitrogen $\left(\mathbf{N}_{2}\right)$}

3.1. Materials and Methods. Poly(vinylpyrrolidone) (PVP, average molecular weight: 1,300,000) was obtained from Aldrich Chemical Co. Dichloromethane (DCM, $\geq 99.5 \%$ ) and ethanol (absolute, $\geq 99.5 \%$ ) were purchased from SigmaAldrich Chemical Co. (USA). The electrospinning apparatus (developed by Institute of Separation Science \& Technology, Erlangen-Nuremberg University, Erlangen, Germany) is identical to that used in our previous work [49].

3.2. Results and Discussions. In our previous study, compressed $\mathrm{N}_{2}$ was applied as an antisolvent in the electrospinning process, but no hollow or porous PVP fibers were obtained [49]. In this work, there were some supplements to the original efforts, but the same electrospinning apparatus and polymer solutions were employed. It is known that the phase behavior of the experimental solvent in $\mathrm{N}_{2}$ intimately affects the formation of PVP fibers. However, to date, only the solubility data of $\mathrm{N}_{2}$ in ethanol has been reported [50]. 


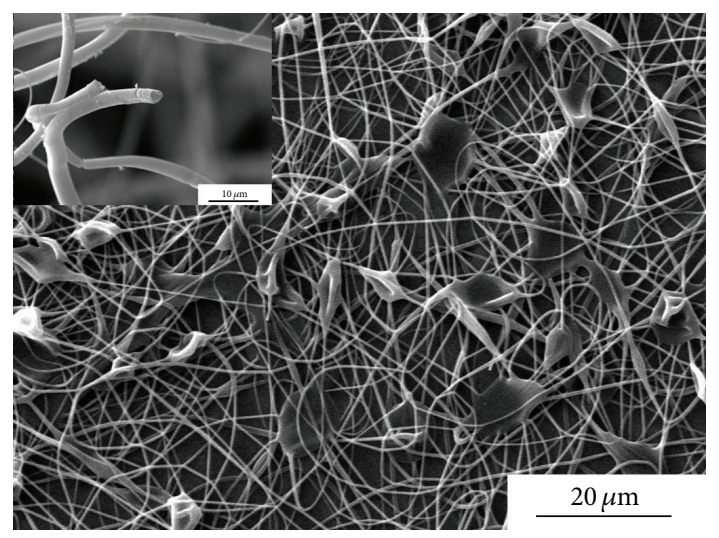

(a)

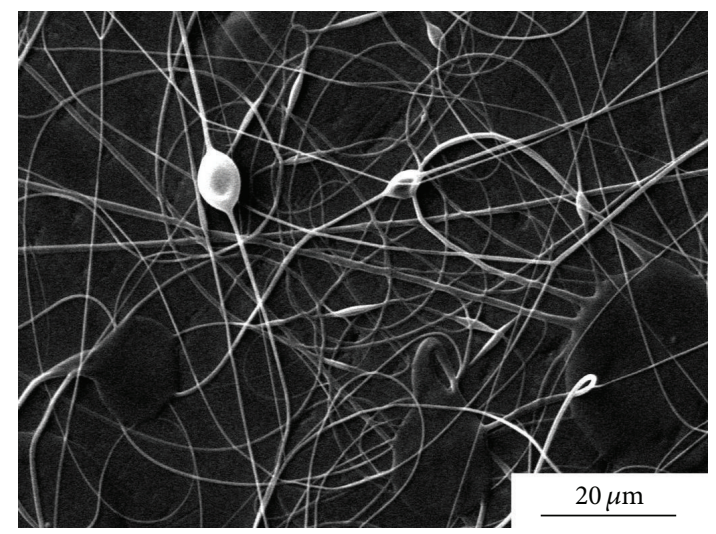

(b)

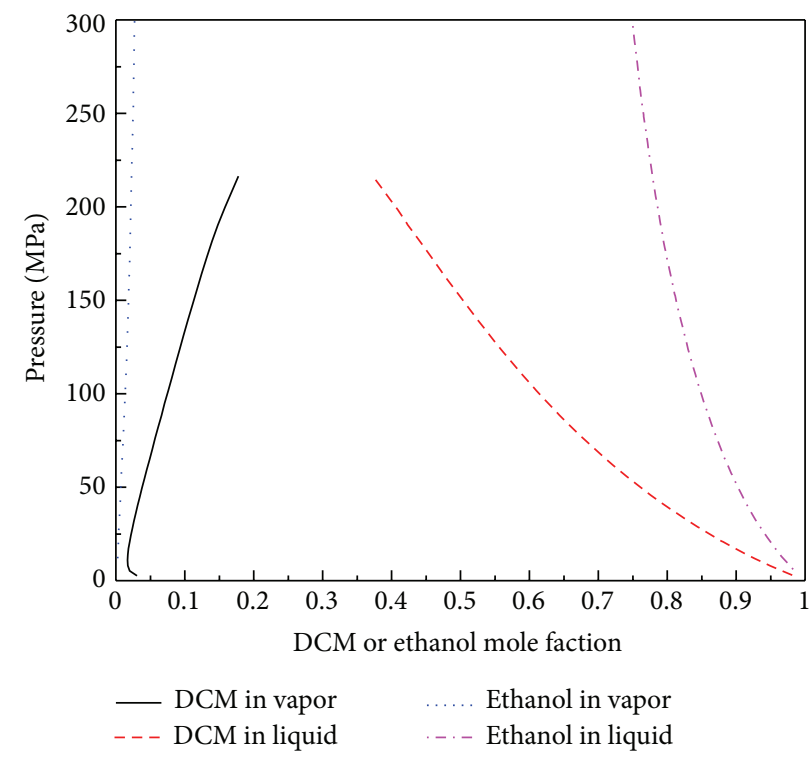

(c)

FIgURE 3: SEM of PVP fibers created by electrospinning a 5 wt $\%$ solution into $\mathrm{N}_{2}$ at $298 \mathrm{~K}$ and $0.1 \mathrm{MPa}$ : (a) $\mathrm{N}_{2}$-ethanol solution; (b) $\mathrm{N}_{2}$-DCM solution; and (c) simulated binary phase equilibrium for $\mathrm{N}_{2}$-ethanol and $\mathrm{N}_{2}$-DCM solutions.

The Peng-Robinson equation of state (EOS) was successfully applied to simulate the phase equilibrium for the binary system of $\mathrm{N}_{2}$ and the solvent [49]. In this work, ASPEN PLUS 2006 was also used together with the Peng-Robinson EOS for simulating the binary phase behavior.

Figure 2 shows the PVP fibers produced by electrospinning a PVP-DCM solution into compressed $\mathrm{N}_{2}$. Polymer fibers are seen to fuse with polymer beads at $2.5 \mathrm{MPa}$ and $5 \mathrm{MPa}$ (Figures 2(a) and 2(b)). Figure 2(d) shows that little DCM diffused into the $\mathrm{N}_{2}$-rich phase and small quantities of $\mathrm{N}_{2}$ appear near the surface of the jet saturated with DCM under low operating gas pressure. It appeared that there was not sufficient time for the evaporation of DCM before it reached the oppositely charged collector. At 7.5 MPa (Figure 2(c)), PVP fibers readily formed without beads, even though some fibers fused together. This suggested that the jet remained liquid-like when it hit the target [44]. At 7.5 MPa and $298 \mathrm{~K}$, the simulated solubility of $\mathrm{N}_{2}$ in the DCMrich phase was found to be about $5 \mathrm{wt} \%$, and the simulated solubility of DCM in $\mathrm{N}_{2}$-rich phase was only $2 \mathrm{wt} \%$ (Figure $2(\mathrm{~d})$ ), which is higher than that at $2.5 \mathrm{MPa}$ and $5 \mathrm{MPa}$. That is why PVP fibers without beads can be produced at $7.5 \mathrm{MPa}$, but not at $2.5 \mathrm{MPa}$ and $5 \mathrm{MPa}$. In addition, the solubility of $\mathrm{N}_{2}$ in the DCM-rich phase was obviously lower than that of air. This could explain why fibers without beads can be produced under an ambient air environment. In our previous work, the phase equilibrium of $\mathrm{CO}_{2}$-DCM binary system was simulated [49]. The binary critical pressure at $298 \mathrm{~K}$ for the $\mathrm{CO}_{2}$-DCM system was found to be $6.5 \mathrm{MPa}$, at which DCM and $\mathrm{CO}_{2}$ are mutually miscible. However, in this present study, we found that the binary critical pressure of DCM-N $\mathrm{N}_{2}$ and DCM-air systems' is more than $100 \mathrm{MPa}$, which is higher than the operating pressure used in this study. This fact may explain why porous or hollow fibers can be obtained in a bath of compressed $\mathrm{CO}_{2}$, but not in $\mathrm{N}_{2}$ or air.

Since evaporation of the solvent during the electrospinning process changes the viscoelastic properties of 
the polymer solutions [51], we chose to use ethanol and DCM in this study. Figure 3 shows the morphology of PVP fibers created from electrospinning PVP-ethanol and PVPDCM solution into $\mathrm{N}_{2}$ bath at $298 \mathrm{~K}$ and $0.1 \mathrm{MPa}$. Compared with PVP-ethanol, PVP-DCM system results in a wider distribution of fiber diameters and fewer spindles or beads. Also, the fibers are solid core without any porous structure on the surface (Figure 3(a)). Figure 3(c) shows that the miscibility of $\mathrm{N}_{2}$ and DCM is obviously better than that of $\mathrm{N}_{2}$ and ethanol, which may explain why there are fewer beads in $\mathrm{N}_{2}$ and DCM binary systems. The diffusion of gas into the polymer jet may induce phase separation and some special internal structures (hollow or porous). However, there is no binary critical pressure, under which the composition in liquid and vapor is similar, even though the pressure is higher than $200 \mathrm{MPa}$ (Figure 3(c)). The relative immiscibility of both binary systems demonstrates why porous or hollow fibers cannot be produced in compressed $\mathrm{N}_{2}$. The binary critical pressure at $298 \mathrm{~K}$ for $\mathrm{CO}_{2}-\mathrm{DCM}$ is about $6 \mathrm{MPa}$, and for $\mathrm{CO}_{2}$ ethanol is $6.5 \mathrm{MPa}$, which indicates that the two systems are miscible, and that the diffusion of $\mathrm{CO}_{2}$ into polymer solution jet easily induces phase separation [49].

Based on the experimental results and phase equilibrium simulation, it can be concluded that $\mathrm{N}_{2}$ is not a good choice as an antisolvent for producing hollow or porous nanofibers. The miscibility of the solvent in near-critical or supercritical fluids has an important influence on the inner structure of polymer fibers.

\section{Conclusions and Perspectives}

Electrospinning is one of the most popular methods for producing polymer nanofibers. Supercritical fluid-assisted electrospinning is still a new process, representing an evolution of traditional electrospinning. This new method is advancing the techniques for producing hollow or porous nanofibers in a single step. The fibers' morphology can be easily controlled by regulating the temperature and pressure of supercritical fluids. It can completely eliminate employment of an organic solvent, as demonstrated by the work of Levit and Tepper [40].

In the future, it is conceivable that the use of supercritical fluid-assisted electrospinning to produce nanofibers with specific microstructures will have great impact on technologies such as, filtration, tissue engineering, and drug delivery. It has been shown that the phase behavior of the solvent and polymer in supercritical fluids has great influences on the morphologies of the fibers. Consequently, more fundamental efforts must be exerted in exploiting phase separation under the supercritical conditions. This work provides the necessary information for designing electrospinning processes in supercritical fluids.

\section{Acknowledgments}

Financial supports from the Ministry of Education (Doctoral Special Research Foundation no. 20110201110032), China and Xi'an Jiaotong University (New Teacher Research Support
Plan no. 08141002 and International Cooperation Project no. 2011jdhz37) are gratefully acknowledged.

\section{References}

[1] A. Frenot and I. S. Chronakis, "Polymer nanofibers assembled by electrospinning," Current Opinion in Colloid and Interface Science, vol. 8, no. 1-2, pp. 64-75, 2003.

[2] S. H. Tan, R. Inai, M. Kotaki, and S. Ramakrishna, "Systematic parameter study for ultra-fine fiber fabrication via electrospinning process," Polymer, vol. 46, no. 16, pp. 6128-6134, 2005.

[3] J. H. He, Y. Q. Wan, and J. Y. Yu, "Scaling law in electrospinning: relationship between electric current and solution flow rate," Polymer, vol. 46, no. 8, pp. 2799-2801, 2005.

[4] D. H. Reneker and A. L. Yarin, "Electrospinning jets and polymer nanofibers," Polymer, vol. 49, no. 10, pp. 2387-2425, 2008.

[5] T. Subbiah, G. S. Bhat, R. W. Tock, S. Parameswaran, and S. S. Ramkumar, "Electrospinning of nanofibers," Journal of Applied Polymer Science, vol. 96, no. 2, pp. 557-569, 2005.

[6] D. H. Reneker, A. L. Yarin, E. Zussman, and H. Xu, "Electrospinning of nanofibers from polymer solutions and melts," Advances in Applied Mechanics, vol. 41, pp. 43-346, 2007.

[7] Z. M. Huang, Y. Z. Zhang, M. Kotaki, and S. Ramakrishna, "A review on polymer nanofibers by electrospinning and their applications in nanocomposites," Composites Science and Technology, vol. 63, no. 15, pp. 2223-2253, 2003.

[8] P. Lu and B. Ding, "Applications of electrospun fibers," Recent Patents on Nanotechnology, vol. 2, no. 3, pp. 169-182, 2008.

[9] N. Bhardwaj and S. C. Kundu, "Electrospinning: a fascinating fiber fabrication technique," Biotechnology Advances, vol. 28, no. 3, pp. 325-347, 2010.

[10] A. H. Touny and S. B. Bhaduri, "A reactive electrospinning approach for nanoporous PLA/monetite nanocomposite fibers," Materials Science and Engineering C, vol. 30, no. 8, pp. 13041312, 2010.

[11] J. Y. Lin, B. Ding, J. Y. Yu, and Y. Hsieh, "Direct fabrication of highly nanoporous polystyrene fibers via electrospinning," ACS Applied Materials and Interfaces, vol. 2, no. 2, pp. 521-528, 2010.

[12] C. H. Kim, Y. H. Jung, H. Y. Kim, D. R. Lee, N. Dharmaraj, and K. E. Choi, "Effect of collector temperature on the porous structure of electrospun fibers," Macromolecular Research, vol. 14, no. 1, pp. 59-65, 2006.

[13] K. Nayani, H. Katepalli, C. S. Sharma, A. Sharma, S. Patil, and R. Venkataraghavan, "Electrospinning combined with nonsolvent-induced phase separation to fabricate highly porous and hollow submicrometer polymer fibers," Industrial and Engineering Chemistry Research, vol. 51, no. 4, pp. 1761-1766, 2012.

[14] S. G. Cao, B. H. Hu, and H. Q. Liu, "Fabrication of nano-porous structured polylactide (PLLA) fibers through electrospinning," Acta Polymerica Sinica, no. 10, pp. 1193-1198, 2010.

[15] Y. Z. Zhang, Y. Feng, Z. M. Huang, S. Ramakrishna, and C. T. Lim, "Fabrication of porous electrospun nanofibres," Nanotechnology, vol. 17, no. 3, pp. 901-908, 2006.

[16] M. Bognitzki, W. Czado, T. Frese et al., "Nanostructured fibers via electrospinning," Advanced Materials, vol. 13, no. 1, pp. 7072, 2001.

[17] S. O. Han, W. K. Son, J. H. Youk, T. S. Lee, and W. H. Park, "Ultrafine porous fibers electrospun from cellulose triacetate," Materials Letters, vol. 59, no. 24-25, pp. 2998-3001, 2005. 
[18] M. Srinivasarao, D. Collings, A. Philips, and S. Patel, "Threedimensionally ordered array of air bubbles in a polymer film," Science, vol. 292, no. 5514, pp. 79-83, 2001.

[19] C. L. Casper, J. S. Stephens, N. G. Tassi, D. B. Chase, and J. F. Rabolt, "Controlling surface morphology of electrospun polystyrene fibers: effect of humidity and molecular weight in the electrospinning process," Macromolecules, vol. 37, no. 2, pp. 573-578, 2004.

[20] S. Megelski, J. S. Stephens, D. B. Chase, and J. F. Rabolt, "Microand nanostructured surface morphology on electrospun polymer fibers," Macromolecules, vol. 35, no. 22, pp. 8456-8466, 2002.

[21] M. Bognitzki, T. Frese, M. Steinhart et al., "Preparation of fibers with nanoscaled morphologies: electrospinning of polymer blends," Polymer Engineering and Science, vol. 41, no. 6, pp. 982989, 2001.

[22] H. R. Pant, M. P. Neupane, B. Pant et al., "Fabrication of highly porous poly (epsilon-caprolactone) fibers for novel tissue scaffold via water-bath electrospinning," Colloids and Surfaces $B$, vol. 88, no. 2, pp. 587-592, 2011.

[23] S. Moon, J. Choi, and R. J. Farris, "Highly porous polyacrylonitrile/polystyrene nanofibers by electrospinning," Fibers and Polymers, vol. 9, no. 3, pp. 276-280, 2008.

[24] L. F. Zhang and Y. L. Hsieh, "Nanoporous ultrahigh specific surface polyacrylonitrile fibres," Nanotechnology, vol. 17, no. 17, pp. 4416-4423, 2006.

[25] S. O. Han, W. K. Son, D. Cho, J. H. Youk, and W. H. Park, "Preparation of porous ultra-fine fibres via selective thermal degradation of electrospun polyetherimide/poly(3-hydroxybutyrateco-3-hydroxyvalerate) fibres," Polymer Degradation and Stability, vol. 86, no. 2, pp. 257-262, 2004.

[26] W. S. Lyoo, J. H. Youk, S. W. Lee, and W. H. Park, "Preparation of porous ultra-fine poly(vinyl cinnamate) fibers," Materials Letters, vol. 59, no. 28, pp. 3558-3562, 2005.

[27] L. Jun, Y. Zhang, Y. Hao, L. Cheng, and J. J. Zhang, "Preparation of porous electro-spun UPM fibers via photocrosslinking," Journal of Applied Polymer Science, vol. 112, no. 4, pp. 2247-2254, 2009.

[28] M. Mehraban, A. Zadhoush, S. A. H. Ravandi, R. Bagheri, and A. H. Tehrani, "Preparation of porous nanofibers from electrospun polyacrylonitrile/calcium carbonate composite nanofibers using porogen leaching technique," Journal of Applied Polymer Science, vol. 128, no. 2, pp. 926-933, 2013.

[29] Z. M. Xu, X. L. Jiang, T. Liu et al., "Foaming of polypropylene with supercritical carbon dioxide," Journal of Supercritical Fluids, vol. 41, no. 2, pp. 299-310, 2007.

[30] A. I. Cooper, "Porous materials and supercritical fluids," Advanced Materials, vol. 15, no. 13, pp. 1049-1059, 2003.

[31] S. Partap, I. Rehman, J. R. Jones, and J. A. Darr, "'Supercritical carbon dioxide in water' emulsion-templated synthesis of porous calcium alginate hydrogels," Advanced Materials, vol. 18, no. 4, pp. 501-504, 2006.

[32] P. van de Witte, P. J. Dijkstra, J. W. A. van den Berg, and J. Feijen, "Phase separation processes in polymer solutions in relation to membrane formation," Journal of Membrane Science, vol. 117, no. 1-2, pp. 1-31, 1996.

[33] H. J. Lee, B. Jung, Y. S. Kang, and H. Lee, "Phase separation of polymer casting solution by nonsolvent vapor," Journal of Membrane Science, vol. 245, no. 1-2, pp. 103-112, 2004.

[34] E. Reverchon, "Supercritical antisolvent precipitation of microand nano-particles," Journal of Supercritical Fluids, vol. 15, no. 1, pp. 1-21, 1999.
[35] C. F. Kirby and M. A. McHugh, "Phase behavior of polymers in supercritical fluid solvents," Chemical Reviews, vol. 99, no. 2-3, pp. 565-602, 1999.

[36] O. Ayodeji, E. Graham, D. Kniss, J. Lannutti, and D. Tomasko, "Carbon dioxide impregnation of electrospun polycaprolactone fibers," Journal of Supercritical Fluids, vol. 41, no. 1, pp. 173-178, 2007.

[37] Y. K. Park, C. W. Curtis, and C. B. Roberts, "Formation of nylon particles and fibers using precipitation with a compressed antisolvent," Industrial and Engineering Chemistry Research, vol. 41, no. 6, pp. 1504-1510, 2002.

[38] D. J. Dixon and K. P. Johnston, "Formation of microporous polymer fibers and oriented fibrils by precipitation with a compressed fluid antisolvent," Journal of Applied Polymer Science, vol. 50, no. 11, pp. 1929-1942, 1993.

[39] G. Luna-Bárcenas, S. K. Kanakia, I. C. Sanchez, and K. P. Johnston, "Semicrystalline microfibrils and hollow fibres by precipitation with a compressed-fluid antisolvent," Polymer, vol. 36, no. 16, pp. 3173-3182, 1995.

[40] N. Levit and G. Tepper, "Supercritical $\mathrm{CO}_{2}$-assisted electrospinning," Journal of Supercritical Fluids, vol. 31, no. 3, pp. 329-333, 2004.

[41] Z. Shen, B. E. Thompson, and M. A. McHugh, "Electrospinning in near-critical $\mathrm{CO}_{2}$," Macromolecules, vol. 39, no. 25, pp. 85538555, 2006.

[42] M. Mchugh, Z. Shen, D. Gee et al., "Method of producing fibers by electrospinning at high pressures," WO2004US43096, 200412-23.

[43] B. H. Lee, D. Freitag, W. Arlt, and M. McHugh, "Hollow fibers by electrospinning in supercritical $\mathrm{CO}_{2}$," Materials Science, vol. 2, pp. 8555-8565, 2007.

[44] J. Liu, Z. Shen, S. H. Lee, M. Marquez, and M. A. McHugh, "Electrospinning in compressed carbon dioxide: Hollow or open-cell fiber formation with a single nozzle configuration," Journal of Supercritical Fluids, vol. 53, no. 1-3, pp. 142-150, 2010.

[45] Wahyudiono, K. Murakami, S. Machmudah, M. Sasaki, and M. Goto, "Production of nanofibers by electrospinning under pressurized $\mathrm{CO}_{2}$," High Pressure Research, vol. 32, no. 1, pp. 5459, 2012.

[46] A. Z. Chen, Y. Li, F. T. Chau et al., "Microencapsulation of puerarin nanoparticles by poly(l-lactide) in a supercritical $\mathrm{CO}_{2}$ process," Acta Biomaterialia, vol. 5, no. 8, pp. 2913-2919, 2009.

[47] R. Pini, G. Storti, M. Mazzotti, H. Tai, K. M. Shakesheff, and S. M. Howdle, "Sorption and swelling of poly(DL-lactic acid) and poly(lactic-co-glycolic acid) in supercritical $\mathrm{CO}_{2}$ : an experimental and modeling study," Journal of Polymer Science $B$, vol. 46, no. 5, pp. 483-496, 2008.

[48] Wahyudiono, K. Murakami, S. Machmudah, M. Sasaki, and M. Goto, "A dry process for polymer nano-microfibers prepared by electrospinning under pressurized $\mathrm{CO}_{2}$," Japanese Journal of Applied Physics, vol. 51, no. 8, Article ID 08HF07, 5 pages, 2012.

[49] L. Li, J. Xu, T. Fang, J. Geng, D. Freitag, and W. Arlt, "Producing PVP nanofibers by electrospinning in $\mathrm{N}_{2}$," Advanced Materials Research, vol. 560-561, part 2, pp. 701-708, 2012.

[50] K. Fischer and M. Wilken, "Experimental determination of oxygen and nitrogen solubility in organic solvents up to $10 \mathrm{MPa}$ at temperatures between $298 \mathrm{~K}$ and $398 \mathrm{~K}$," The Journal of Chemical Thermodynamics, vol. 33, no. 10, pp. 1285-1308, 2001.

[51] S. Tripatanasuwan, Z. Zhong, and D. H. Reneker, "Effect of evaporation and solidification of the charged jet in electrospinning of poly(ethylene oxide) aqueous solution," Polymer, vol. 48, no. 19, pp. 5742-5746, 2007. 

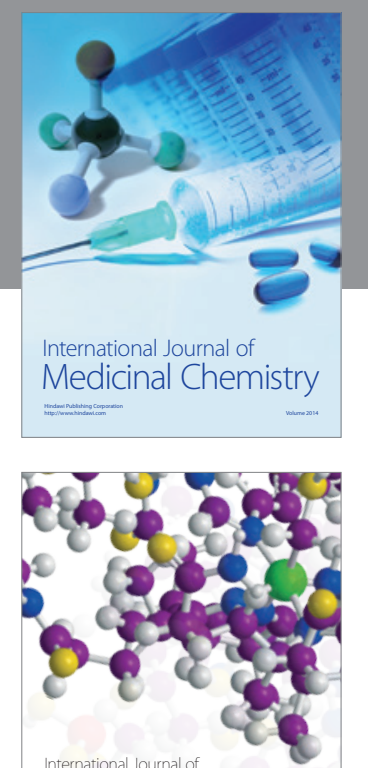

\section{Carbohydrate} Chemistry

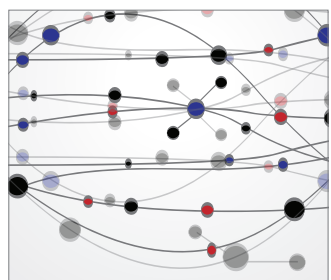

The Scientific World Journal
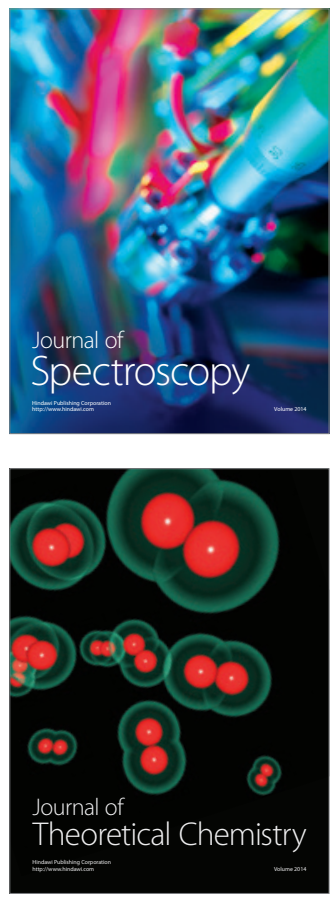
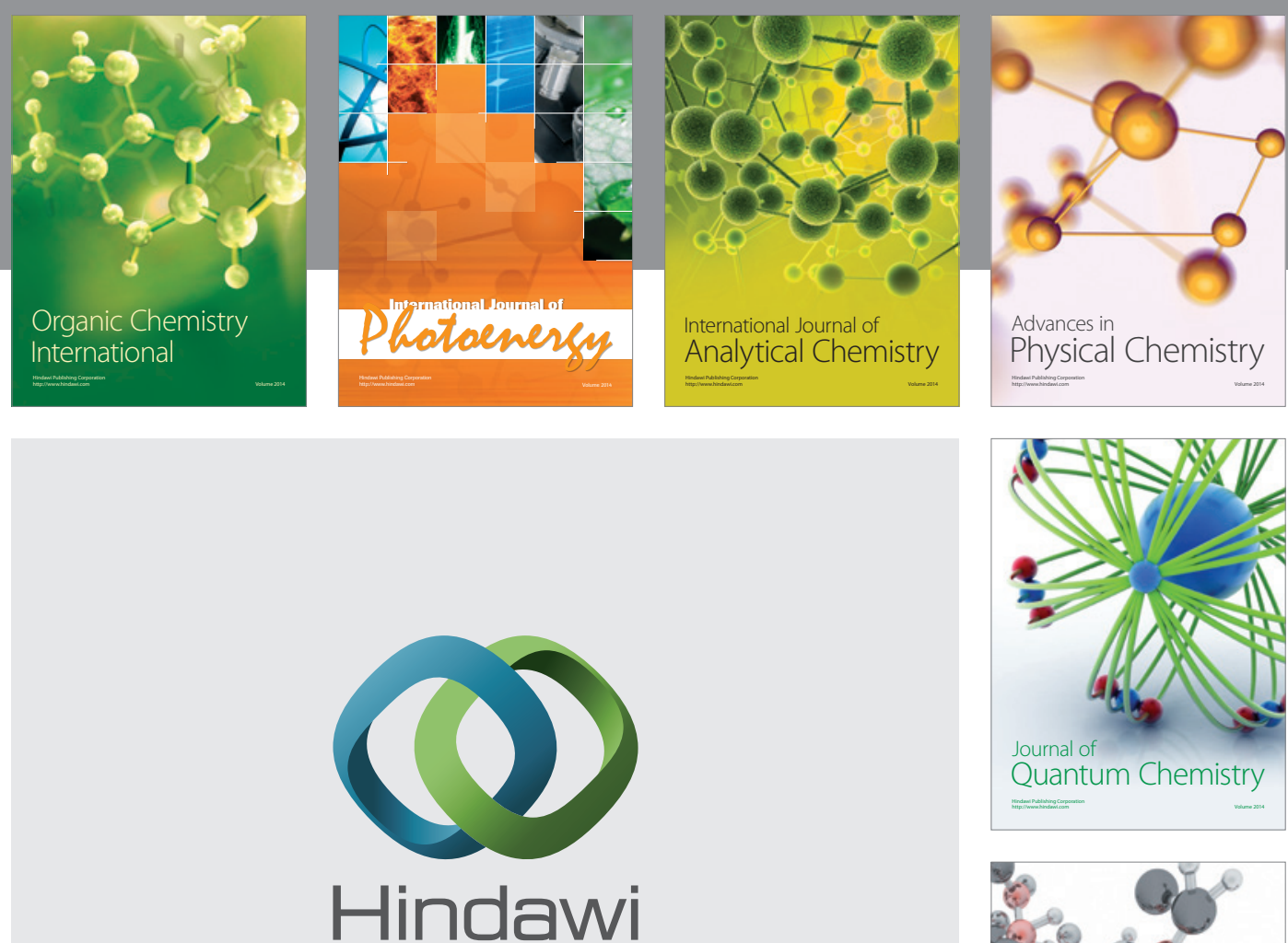

Submit your manuscripts at

http://www.hindawi.com

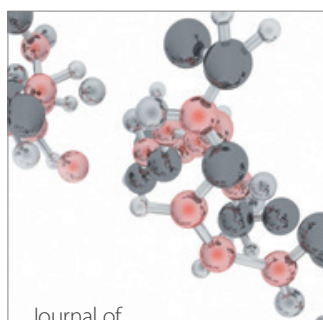

Analytical Methods

in Chemistry

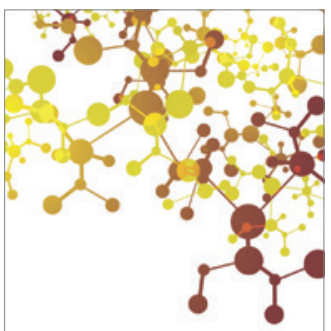

Journal of

Applied Chemistry

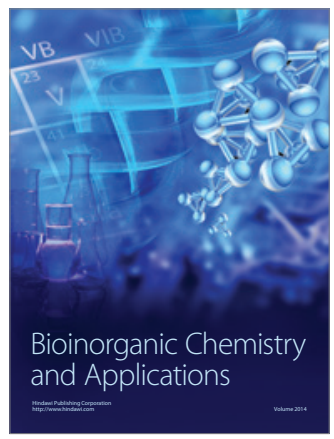

Inorganic Chemistry
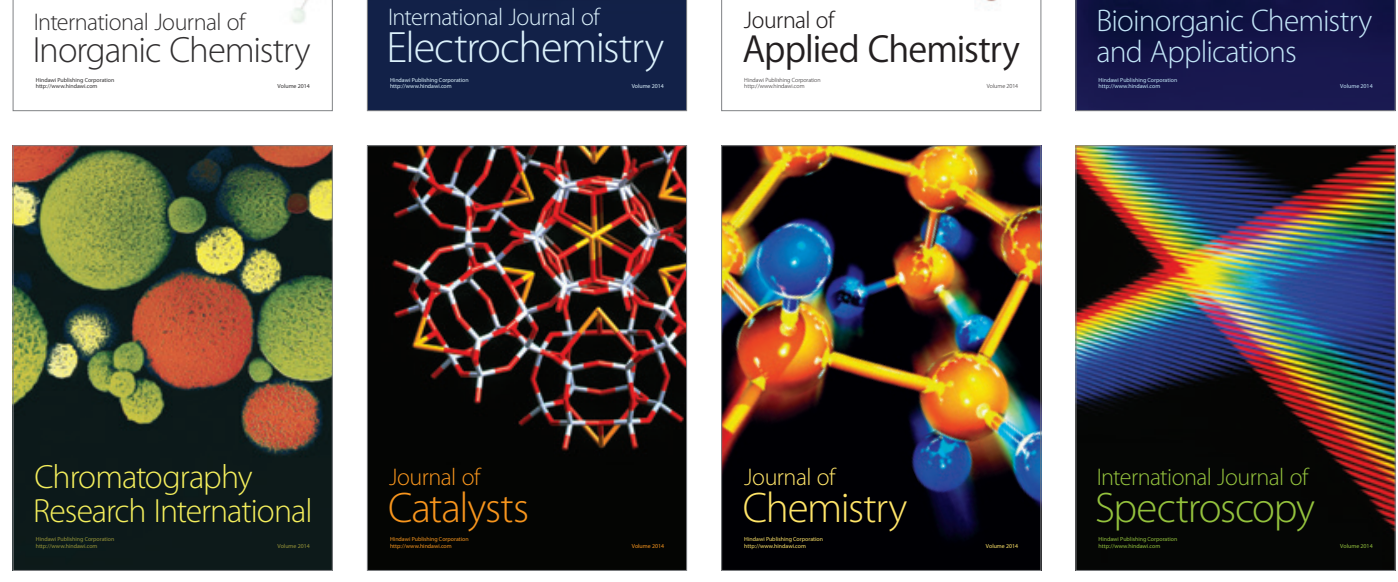